\title{
Research Article \\ Effects of Astaxanthin on Miniature Pig Sperm Cryopreservation
}

\author{
Eunjoo Lee and Daeyoung Kim \\ Department of Life Sciences, College of Bio-Nano Technology, Gachon University, Seongnam 13120, Republic of Korea \\ Correspondence should be addressed to Daeyoung Kim; davekim@gachon.ac.kr
}

Received 22 September 2017; Revised 14 February 2018; Accepted 11 March 2018; Published 19 April 2018

Academic Editor: Yau Hung Chen

Copyright (c) 2018 Eunjoo Lee and Daeyoung Kim. This is an open access article distributed under the Creative Commons Attribution License, which permits unrestricted use, distribution, and reproduction in any medium, provided the original work is properly cited.

\begin{abstract}
The purpose of this study is to evaluate the effects of astaxanthin added to freezing buffer on semen parameters, total sperm oxidation stress after postthawing of boar sperm, and lipid peroxidation (LPO) which is caused by reactive oxygen species (ROS) in sperm membrane. Varying concentrations of astaxanthin $(0,10,50,100$, and $500 \mu \mathrm{M})$ were used in the freezing buffer during cryopreservation to protect the DNA of thawed miniature pig sperm. Semen parameter was measured using computerassisted sperm analysis (CASA) for sperm motility, and then ROS rate and oxidative stress of boar sperm were determined using fluorescence-activated cell sorting (FACS). Sperm motility was higher $(p<0.05)$ in the astaxanthin group than in the control group. Sperm motility and the number of progressive motile sperm were higher $(p<0.05)$ in the astaxanthin $500 \mu \mathrm{M}$ group than in the control group. In ROS evaluation, the astaxanthin group had lower intracellular $\mathrm{O}_{2}$ and $\mathrm{H}_{2} \mathrm{O}_{2}$ in viable sperm. Yo-Pro-I/HE and $\mathrm{PI} / \mathrm{H} 2 \mathrm{DCFDA}$ staining as revealed using flow cytometry was lower in astaxanthin groups than in the other groups. As a result, we found that astaxanthin could protect the sperm plasma membrane from free radicals and LPO during boar sperm postthawing.
\end{abstract}

\section{Introduction}

Thanks to the development of biotechnology and the area of biomedicine, stem cell culture techniques and technologies for the production of animals for organ transplantation and the mass production of therapeutic materials using transgenic animals have developed [1]. Meanwhile, miniature pigs produced using new technologies are anatomically and physiologically similar to humans and thus are used as experimental animals for studies on biomedicine and are receiving attention as animals for interspecific organ transplantation.

In the case of miniature pigs mostly produced through natural mating, difficulties are being experienced in securing sires and producing litters. Therefore, artificial insemination (AI) is necessary to improve the productivity of miniature pigs and to use good sires. Methods of using semen for AI include using liquid sperm and preserving sperm as frozen sperm. Although AI using liquid sperm is universally used, due to the limitation of this method that sperm can be preserved only for a short period of time, frozen storage methods that can supplement the limited longevity in vitro of collected semen are being reported [2].
Although frozen storage is an efficient technology, it causes damage to cell membranes, abnormal enzyme activity, and damage to DNA due to the cold shock resulting from drastic temperature changes [3-9]. In addition, due to the increase in reactive oxygen species (ROS) occurring in freezing procedures, sperm motility, survivability, fertilizing capacity, and functions decline after freeze-thawing [10].

Although AI using frozen sperm is commonly used in the case of cattle, it cannot be easily used in clinics in the case of pigs because artificial fertilization rates are low since the oxidative substances formed after freeze-thawing cause stress to sperm [11-14]. Compared to other livestock species, pig semen responds to harmful active oxygen more sensitively because pig sperm contain higher ratios of unsaturated fatty acid in their cell membranes but have relatively fewer antioxidants. Frozen storage has been reported to promote sperm cell membrane lipid oxidation and drastically reduce sperm motility and survivability [15].

Antioxidants remove oxidative substances in sperm and fight against ROS to suppress sperm cell membrane lipid oxidation, thereby enabling sperm to maintain their shapes and functions [16, 17]. Recently, studies indicating that 
diverse antioxidants can mitigate lipid oxidation occurring due to active oxygen have been actively conducted [18]. $\alpha$ Tocopherol, albumin, ascorbic acid, taurine, and hypotaurine are known as antioxidants that mitigate ROS that causes oxidation in sperm cell membranes. Among them, $\alpha$ tocopherol (vitamin E) mainly exists in the cell membrane and suppresses lipid oxidation as it has antioxidant functions. Although $\alpha$-tocopherol's functions in cells are well known, their functions in sperm are not known very well. Taurine and hypotaurine play the role of protecting sperm from lipid oxidation [19-22]. Meanwhile, astaxanthin (AXT, $\mathrm{C}_{4} 0 \mathrm{H}_{52} \mathrm{O}_{4}$, MW 596.84), which is a carotenoid component known as a powerful antioxidative substance, is a natural carotenoid antioxidant that can be extracted from crustaceans or microalgae and is a brilliant red lipid-soluble substance. AXT has a strong antioxidative activity with a better ability to remove $\mathrm{O}_{2}$ compared to vitamin $\mathrm{E}[23,24]$, and it plays the role of preventing lipid oxidation from occurring in cell membranes [25-27].

Although many studies of AXT have been reported, results that demonstrate their antioxidative effects are still insufficient. Therefore, in the present study, to establish stable frozen storage methods for mass propagation of miniature pigs, attempts were made to examine the effects of AXT as antioxidants added to frozen storage solutions during manufacturing on sperm survivability, sperm cell membranes' integrity, ROS occurrence, and lipid oxidation in sperm cells after thawing.

\section{Materials and Methods}

2.1. Chemicals. All chemicals were purchased from SigmaAldrich if not mentioned otherwise.

2.2. Semen Collection. The pig semen used in the present study was collected from PWG miniature pigs being raised at Kangwon National University through a penis hand pressing method using a dummy and was transported to the laboratory in Incheon while being maintained at $17^{\circ} \mathrm{C}$. Using computer-assisted sperm analysis (CASA, Hamilton Thorne, Inc., HTM-HELOS, Beverly, MA, USA), only those semen samples with $80 \%$ or higher sperm motility and $70 \%$ or higher anterograde movements were used.

2.3. Astaxanthin Preparation. AXT ( $3,3^{\prime}$-dihydroxy- $\beta, \beta$-carotene- $4,4^{\prime}$-dione), known as a high-value carotenoid pigment extracted from green algae especially from Haematococcus species, has widely been studied in several fields including food supplements, cosmetics, and pharmaceutical industries. The photosynthetic unicellular green algae $H$. lacustris (UTEX 16) were purchased from the Culture Collection of Algae at the University of Texas at Austin. To obtain microalgal biomass, a single colony of $H$. lacustris grown on an agar plate was cultured in modified Bold's basal medium (MBBM) as described in a previous study [23]. Compact fluorescent lamps (Model DULUX L ${ }^{\circledR}$, OSRAM Korea, Ansan, Korea) were used for photobioreactors as the external illumination. The cells were then inoculated at a density of $2 \times 10^{4}$ cells $\mathrm{mL}^{-1}$ into $500 \mathrm{~mL}$ of bubble column photobioreactor containing $400 \mathrm{~mL}$ of culture broth, providing $0.2 \mathrm{v} / \mathrm{v} / \mathrm{m}$ (volume per volume per minute) aeration containing $5 \% \mathrm{CO}_{2}$ gas and 95\% air under constant continuous light irradiance as described above. Samples were collected and analyzed daily to observe the process of the cultures and AXT accumulation in $H$. lacustris cells. The concentration of AXT following acetone extraction of AXT from the cells was estimated by a calibration curve using synthetic AXT (A9335, Sigma Chemical Co., St. Louis, MO, USA) as a standard following the calibration: AXT concentration $\left(\mathrm{mg} \mathrm{L}^{-1}\right)=0.0045 \times$ OD475. For in vitro assay, AXT was extracted from the cells using a simple process. Briefly, cells (1.0 g) were placed in a mortar and frozen with liquid nitrogen $(50 \mathrm{~mL})$. Using a mortar bar, cells were crushed and destroyed by hand grinding. Freezingthawing-grinding processes were repeated five times and cells were suspended in ethanol (99\%) to extract AXT from the crushed cells. The concentration of AXT was measured following the simple equation described above $[28,29]$.

2.4. Diluent and Frozen Storage Solution. For the pig semen, modified Modena B (mMB: 6 g glucose, $0.45 \mathrm{~g}$ EDTA, $1.38 \mathrm{~g}$ sodium citrate, $0.2 \mathrm{~g}$ sodium bicarbonate, $1 \mathrm{~g}$ Tris base, $0.5 \mathrm{~g}$ citric acid, $0.01 \mathrm{~g}$ cysteine, $0.8 \mathrm{~g}$ BSA, and $0.06 \mathrm{~g}$ kanamycin sulfate, $\mathrm{pH} 7$ ) was used as a basic diluent, lactose-egg yolk (LEY extender: $80 \% \mathrm{v} / \mathrm{v}$ lactose solution [310 mM] and $20 \%$

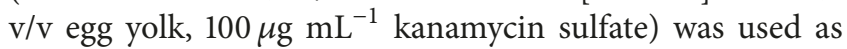
a primary frozen storage solution, and LEY-glycerol-OrvusES-Paste (LEYGO: 89.5\% v/v LEY; 9\% v/v glycerol; 1.5\% v/v Orvus ES Paste (OEP, Nova Chemical Sales, Inc., Scituate, $\mathrm{MA}$ ); $100 \mathrm{mM}$ trehalose; and $0,10,50,100$, and $500 \mu \mathrm{M}$ of AXT) was used as a secondary frozen storage solution.

2.5. Preparation of Pig Semen. The pig semen was diluted with $\mathrm{mMB}$ solution at a ratio of $1: 3$ and subjected to centrifugation $\left(400 \times \mathrm{g}, 10 \mathrm{~min}, 24^{\circ} \mathrm{C}\right)$. The semen was washed using diluted mMB solution 3-5 times depending on semen conditions. After washing, the semen was diluted with LEY so that the number of sperm became $1 \times 10^{9} / \mathrm{mL}$ and was quantified. The sperm-LEY solution was cooled to become $4^{\circ} \mathrm{C}$ by gradually reducing its temperature at a rate of $1^{\circ} \mathrm{C}$ per five minutes in ice water. Thereafter, the solution was mixed with LEYGO added with AXT at concentrations of $0,10,50,100$, and $500 \mu \mathrm{M}$, respectively, at a ratio of $1: 1$. The sperm-LEYGO mixture solutions were put into $0.5 \mathrm{~mL}$ straws, prefrozen for five minutes with the chill of liquid nitrogen at approximately $5 \mathrm{~cm}$ above a Styrofoam box containing liquid nitrogen, and stored in liquid nitrogen.

2.6. Thawing of Frozen Pig Semen and Sperm Motility Test. Sperm motility was measured through computer-assisted sperm analysis (CASA). The straws kept frozen were thawed by immersion in a constant-temperature water tank preheated to $50^{\circ} \mathrm{C}$ for 10 seconds, put into $15 \mathrm{~mL}$ tubes, diluted with $10 \mathrm{~mL}$ of $\mathrm{mMB}$, and left in a constant-temperature water tank preheated to $37^{\circ} \mathrm{C}$ for $5-10 \mathrm{~min}$. When the temperature of the diluted sperm became $37^{\circ} \mathrm{C}$, the solution was subjected to centrifugation $(13,000 \mathrm{rpm}, 5 \mathrm{~min})$ and diluted so that the 
TABLE 1: Effects of astaxanthin (AXT) on standard sperm parameters (mean \pm SD).

\begin{tabular}{lccccc}
\hline Sperm treatment & Motility $(\%)$ & Progressive motility $(\%)$ & VAP $\left(\mu \mathrm{ms}^{-1}\right)$ & VSL $^{\left(\mu \mathrm{ms}^{-1}\right)}$ & ${\text { VCL }\left(\mu \mathrm{ms}^{-1}\right)}^{\mathrm{c}}$ \\
\hline Fresh & $93.4 \pm 0.6^{\mathrm{c}}$ & $71.0 \pm 9.2^{\mathrm{c}}$ & $100.3 \pm 15.6$ & $70.1 \pm 15.7$ & $182.6 \pm 30.8$ \\
Control & $49.8 \pm 4.0^{\mathrm{a}}$ & $33.4 \pm 2.5^{\mathrm{ab}}$ & $99.3 \pm 9.6$ & $63.4 \pm 7.7$ & $180.9 \pm 12.5$ \\
AXT $10 \mu \mathrm{M}$ & $42.0 \pm 11.8^{\mathrm{a}}$ & $27.0 \pm 7.2^{\mathrm{a}}$ & $92.7 \pm 4.5$ & $58.7 \pm 1.7$ & $178.2 \pm 10.3$ \\
AXT $50 \mu \mathrm{M}$ & $55.7 \pm 2.5^{\mathrm{ab}}$ & $35.7 \pm 2.1^{\mathrm{ab}}$ & $99.7 \pm 9.6$ & $60.4 \pm 5.6$ & $195.5 \pm 15.9$ \\
AXT $100 \mu \mathrm{M}$ & $52.7 \pm 3.0^{\mathrm{ab}}$ & $31.0 \pm 5.3^{\mathrm{ab}}$ & $98.5 \pm 5.0$ & $56.6 \pm 7.6$ & $192.9 \pm 9.2$ \\
AXT $500 \mu \mathrm{M}$ & $66.0 \pm 1.7^{\mathrm{b}}$ & $45.7 \pm 2.5^{\mathrm{b}}$ & $110.4 \pm 11.5$ & $70.8 \pm 5.9$ & $203.4 \pm 26.0$ \\
\hline
\end{tabular}

VAP: average-path velocity; VSL: straight-line velocity; VCL: curvilinear velocity. The results are expressed as means \pm SEM of a total number of analyzed boar sperm of 14660. Motility means sperm's ability to move spontaneously and actively, consuming energy in the process; progressive motility means sperm's ability to swim fast in a straight line; VAP means the mean velocity of the sperm head along its average trajectory; VSL means the mean path velocity of the sperm head along a straight line from its first to its last position; VCL means the mean path velocity of the sperm head along its trajectory. a, b, and $c$ indicate difference $P<0.05$

number of sperm became $5 \times 10^{7} \mathrm{~mL}^{-1}$ by adding $\mathrm{mMB}$. Two microliters of the sperm was put into a Leja slide chamber (Leja Products BV, Nieuw-Vennep, Netherlands) preheated to $37^{\circ} \mathrm{C}$ and observed using a microscope. Using CASA analysis, the motility, progressive motility, VAP (path velocity), VSL (straight-line velocity), and VCL (curvilinear velocity) were observed.

2.7. Flow Cytometry for Oxidative Substances and Their Distributions in Pig Sperm. The number of extinct sperm and the quantities of oxidative substances in sperm by the concentration of AXT (provided by Prof. Jaekweon Park, Department of Life Science, Gachon University) added when the sperm were being frozen were measured with FACS (500 series, Beckman Coulter, Inc., FL, USA) using two fluorescent staining methods. Yo-Pro-1 iodide (Yo-Pro-1; Molecular Probes Inc.) $0.05 \mu \mathrm{M}$ and hydroethidine (HE; Molecular Probes Inc., Eugene, OR, USA) $4 \mu \mathrm{M}$ were added to each of the solutions at individual concentrations of AXT solutions and the solutions were made to react for $40 \mathrm{~min}$ at $25^{\circ} \mathrm{C}$ and used to measure the quantities of $\mathrm{O}_{2}{ }^{-}$in the sperm. Thereafter, propidium iodide (PI; Sigma-Aldrich) $0.75 \mu \mathrm{M}$ and $2^{\prime}, 7^{\prime}$-dichlorodihydrofluorescein diacetate $\left(\mathrm{H}_{2} \mathrm{DCFDA}\right.$; Molecular Probes Inc.) $200 \mu \mathrm{M}$ were added to each of the solutions and the solutions were made to react for $10 \mathrm{~min}$ at $37^{\circ} \mathrm{C}$ and used to measure the quantity of $\mathrm{H}_{2} \mathrm{O}_{2}$ in the sperm.

2.8. Statistical Processing. All the data used in the present experiments were statistically processed by conducting variance analyses using the $\mathrm{R}$ statistical program ( $\mathrm{R}$ Development Core Team). The significant difference of the data values obtained through the statistical processing is $p<0.05$.

\section{Results}

3.1. Pig Sperm Motility Test (CASA). The effects of the addition of AXT when frozen storage solutions of pig semen were made on the motility the sperm are as shown in Table 1 . When the frozen storage solutions were made with the addition of AXT, the motility of the sperm was shown to be generally higher than that of the control group. The ratios of sperm that showed movements (motility) were shown to be higher in the AXT $50 \mu \mathrm{M}$, AXT $100 \mu \mathrm{M}$, and AXT $500 \mu \mathrm{M}$ groups than in the control group. Progressive motility was shown to be higher in the AXT $50 \mu \mathrm{M}, \mathrm{AXT} 100 \mu \mathrm{M}$, and AXT $500 \mu \mathrm{M}$ groups than in the control group. In addition, VAP (average-path velocity), VSL (straight-line velocity), and VCL (curvilinear velocity) were also shown to be higher in the AXT $500 \mu \mathrm{M}$ group than in the control group.

3.2. Analysis of Oxidative Substances in Pig Sperm (FACS). The following are the results of FACS analysis of pig sperm added with AXT after being stained using Yo-Pro-1 and $\mathrm{HE}$ (Figure 1). The $\mathrm{O}_{2}{ }^{-}$values in the cells can be seen from the ratios of cells located in the V2 area. Therefore, the experimental groups added with AXT showed significantly higher values than the control group. In addition, $\mathrm{H}_{2} \mathrm{O}_{2}$ in pig sperm cells can be identified by staining pig sperm added with AXT using PI and $\mathrm{H}_{2}$ DCFDA and analyzing the stained pig sperm using FACS (Figure 2). When V3 areas where cells containing many $\mathrm{H}_{2} \mathrm{O}_{2}$ are located were compared with each other, the ratios of $\mathrm{V} 3$ area cells in the control group and the experimental groups were shown to be similar except for the AXT $100 \mu \mathrm{M}$ group that showed a significantly lower value.

3.3. Analysis of ROS in Pig Sperm. ROS levels were examined through two different fluorescent probes: hydroethidine (HE) and $2^{\prime}, 7^{\prime}$-dichlorodihydrofluorescein diacetate ( $\left.\mathrm{H}_{2} \mathrm{DCFDA}\right)$, used to evaluate the intracellular content of superoxide anions $\left(\mathrm{O}_{2}{ }^{-\bullet}\right)$ and peroxides $\left(\mathrm{H}_{2} \mathrm{O}_{2}\right)$, respectively. After incubation, $2 \mu \mathrm{L}$ of the stained sperm was placed on warmed slide glass and examined under a fluorescent microscope (EVOS FL, Thermo Fisher Scientific). We divided sperm staining into four different groups: light green or clear (live cells), dark green (apoptotic cells), red (dead/necrotic cells), and red and green (dead cells) cells (Figure 3).

\section{Discussion}

Semen cryopreservation is an important axis of animal reproductive biotechnology, but its potential must still be realized as much of the mammalian sperm lose fertility in the freezing and thawing process. Cryopreservation of sperm leads to overproduction of reactive oxygen species (ROS), mainly by heat shock, exposure to atmospheric oxygen, and formal plasma elimination. Subsequent oxidative damage 

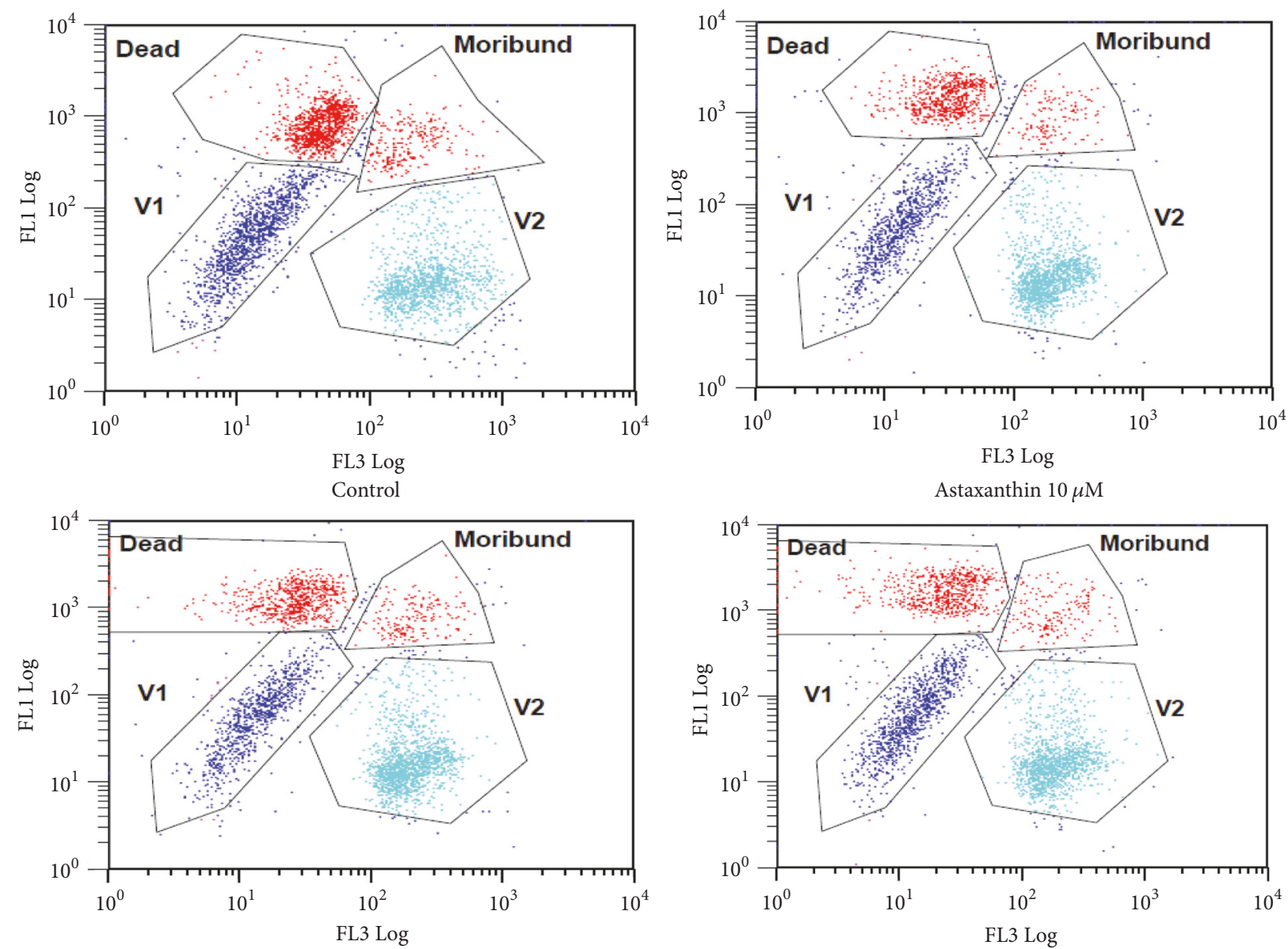

Astaxanthin $50 \mu \mathrm{M}$

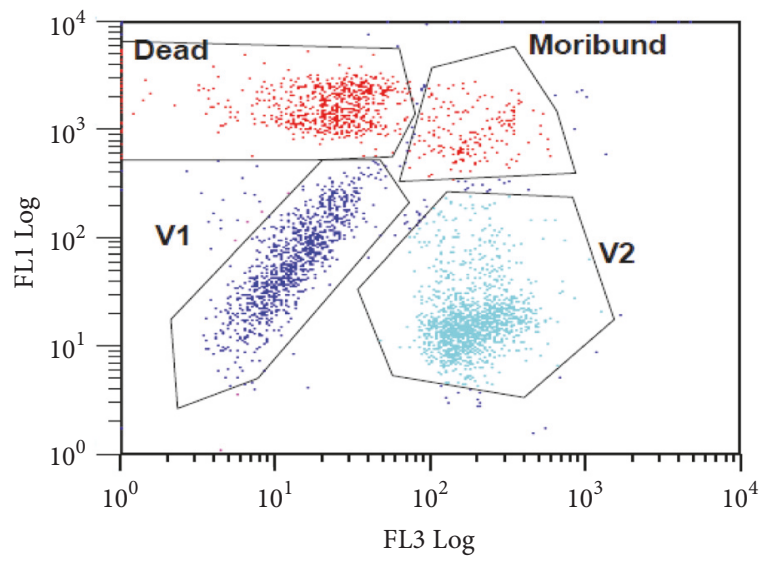

Astaxanthin $100 \mu \mathrm{M}$

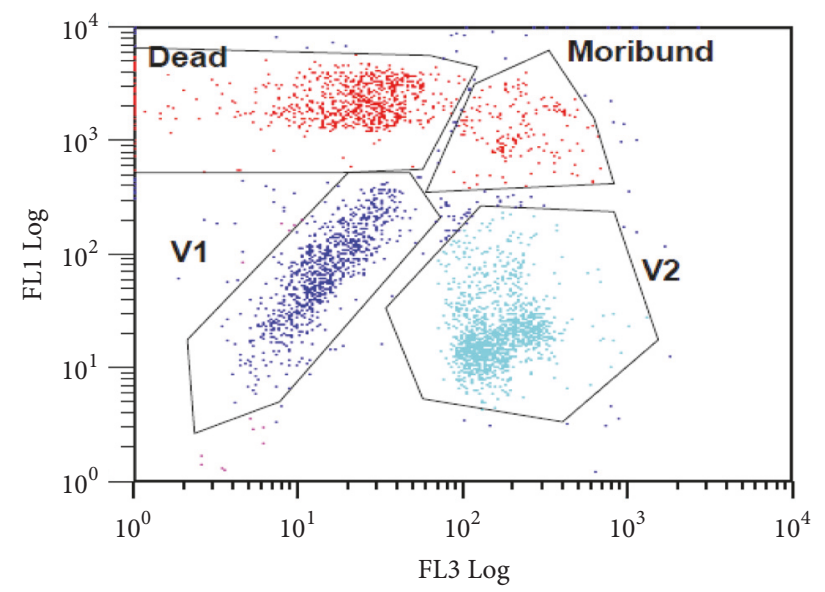

Astaxanthin $500 \mu \mathrm{M}$

FIGURE 1: Flow cytometric analysis of sperm labeled with Yo-Pro-1/HE fluorescence in control and AXT treated groups. V1 region represents viable sperm with a low intracellular $\mathrm{O}_{2}$ radical, and V2 region represents viable sperm with a high intracellular $\mathrm{O}_{2}$ radical, and the upper quadrant Dead and Moribund regions represent dead sperm, in the process of programmed cell death of sperm. Yo-Pro-1/HE fluorescence: measure $\mathrm{O}_{2}$ radical of sperm. Yo-Pro-1: FL1 Log; HE: FL3 Log.

can cause significant changes in sperm motility behavior, membrane integrity, lipid peroxidation (LPO), DNA damage, and apoptosis, ultimately reducing fertility [30].

Although frozen storage methods are highly efficient, they are accompanied by drastic temperature changes. Pig sperm are easily affected by cold shocks and are not sufficiently resistant to low temperatures. Therefore, they are highly likely to become extinct due to differences in intracellular osmotic pressure or damage to DNA in cell nuclei $[3,13]$. Ram, rabbit, and pig sperm are severely damaged 

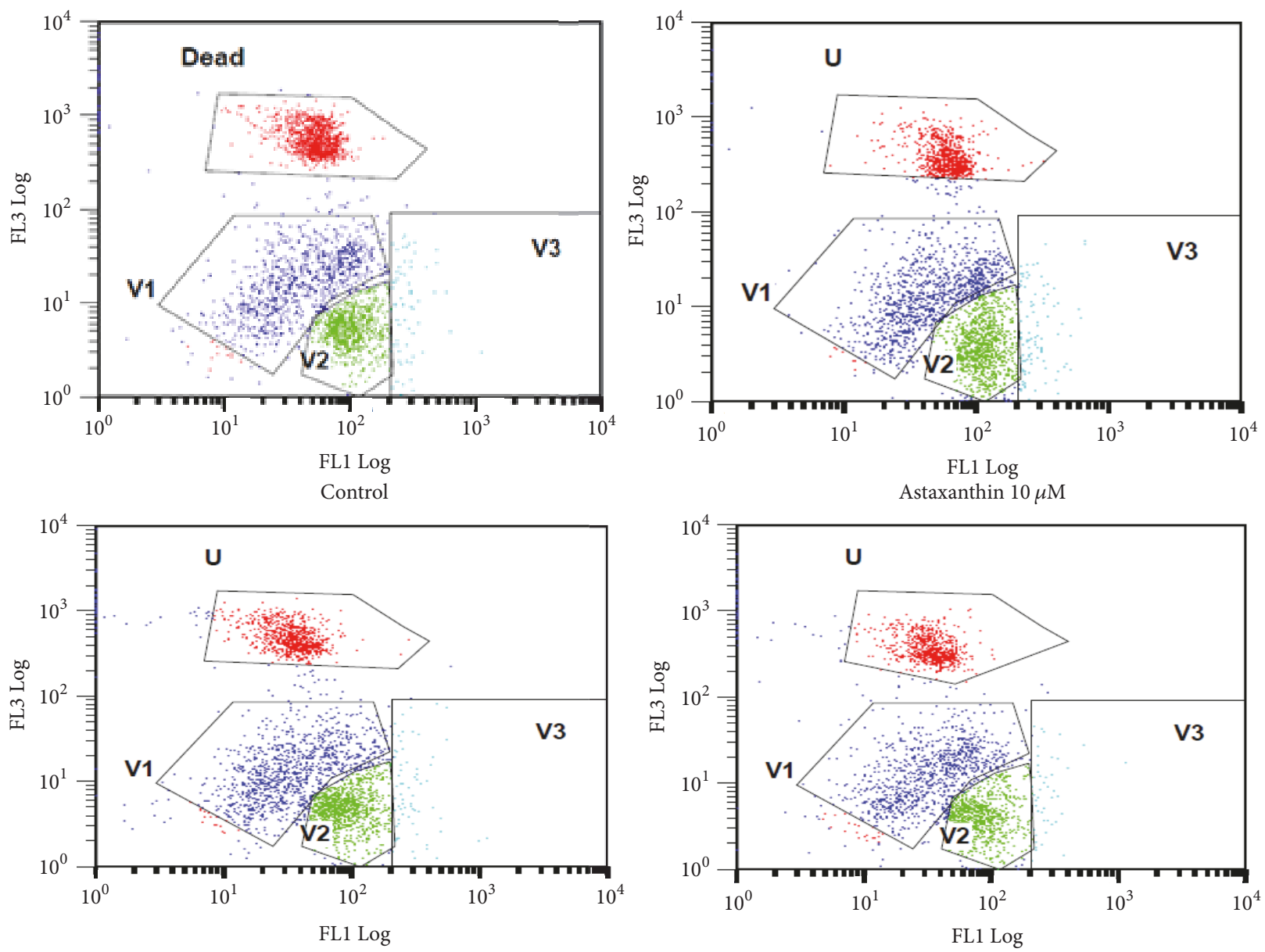

Astaxanthin $50 \mu \mathrm{M}$

Astaxanthin $100 \mu \mathrm{M}$

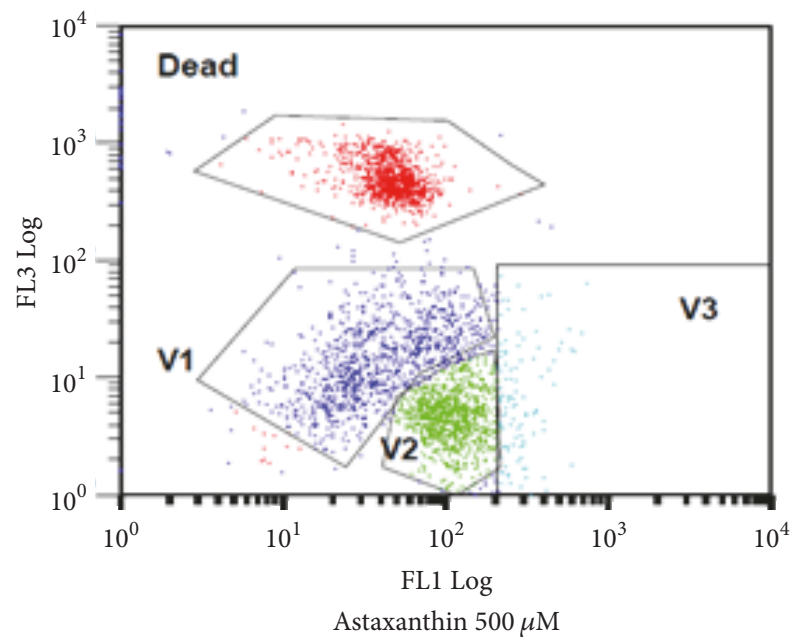

FIGURE 2: Flow cytometric analysis of sperm labeled with $\mathrm{PI} / \mathrm{H}_{2} \mathrm{DCFDA}$ fluorescence in control and AXT treated groups. V1 and V2 regions represent viable sperm with a low intracellular $\mathrm{H}_{2} \mathrm{O}_{2}$ radical, and $\mathrm{V} 3$ region represents viable sperm with a high intracellular $\mathrm{H}_{2} \mathrm{O}_{2}$ radical, and the upper quadrant Dead region represents dead sperm. PI/ $\mathrm{H}_{2}$ DCFDA fluorescence: measure $\mathrm{H}_{2} \mathrm{O}_{2}$ of sperm. PI: FL1 Log; $\mathrm{H}_{2} \mathrm{DCFDA}$ : FL3 Log. 


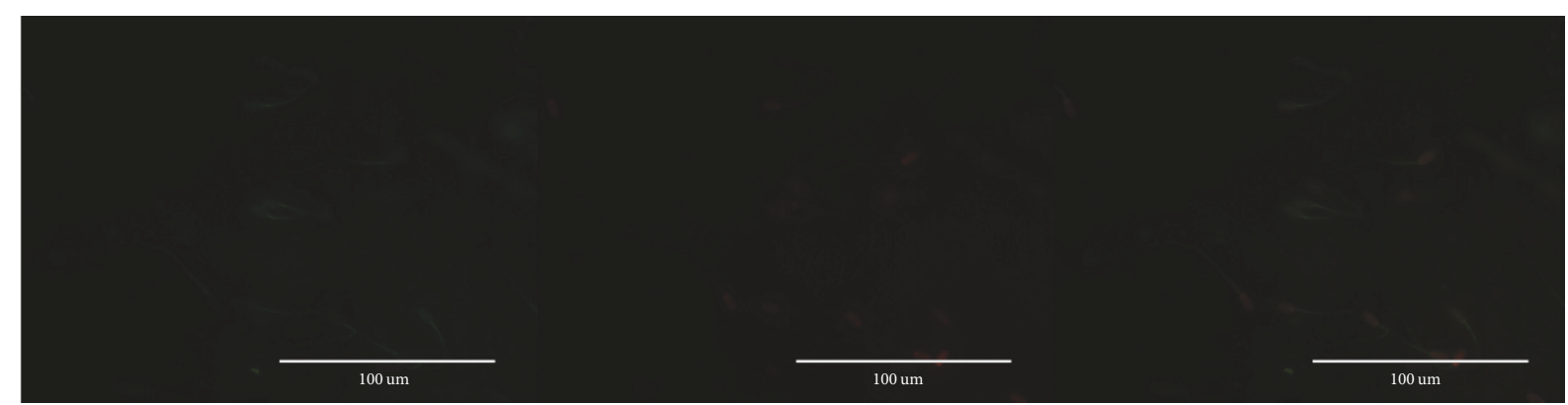

(a)

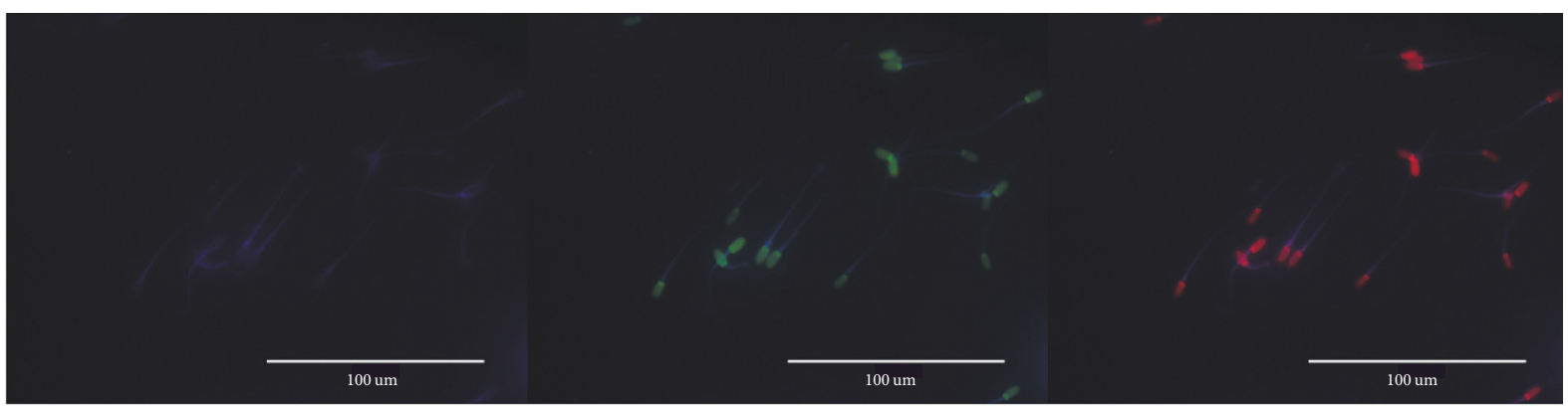

(b)

FIGURE 3: Microscopic view of sperm stained with Yo-Pro-1/HE (a) or PI/ $\mathrm{H}_{2}$ DCFDA (b) fluorescence (EVOS ${ }^{\oplus}$ FL, Thermo Fisher Scientific). The images indicate apoptotic cells (green), whereas dead nonapoptotic cells are red in color. Four populations of sperm were obtained: light green or clear (live cells), dark green (apoptotic cells), red (dead/necrotic cells), and red and green (dead cells).

during the freeze-thawing process and such damage reduces sperm motility [31-33]. Sperm cell membranes have unsaturated fatty acid that can be changed into lipid peroxides. The sperm damaged by the active oxygen generated in the process of sperm freezing are subjected to oxidative stress which causes damage to sperm structures leading to reduced sperm motility [34]. Antioxidative substances prevent lipid oxidation from occurring in sperm cell membranes so that sperm can maintain their metabolic activity and functions. This enhances the survival rates of sperm and maintains their motility after freeze-thawing, thereby enhancing the utility of frozen sperm [35].

Recently, studies have been conducted on the addition of antioxidants during the manufacturing of frozen sperm to improve sperm functions after freeze-thawing. $\alpha$-Tocopherol, taurine, hypotaurine, and trehalose are known as antioxidants that mitigate ROS that causes oxidation in bovine, goat, rabbit, ram, and rat sperm cell membranes [36, 37]. Taurine plays the role of protecting sperm from active oxygen when sperm are exposed to oxygen or during the process of freezethawing. Hypotaurine plays the role of protecting sperm from lipid oxidation. Trehalose increases sperm resistance to damage during freeze-thawing through interactions with phospholipid in sperm cell membranes. Among them, $\alpha$ tocopherol (vitamin E) mainly exists in cell membranes and suppresses lipid oxidation because it has antioxidant functions. Although $\alpha$-tocopherol's functions in cells are well known, their functions in mammalian sperm are not well known [20-22].
The experimental data indicate that when treated with AXT, higher ratios of sperm survived and showed movements in the freeze-thawing process. When the motility of the sperm was analyzed using CASA, it could be seen that the motility was highest when the sperm were treated with AXT at a concentration of $500 \mu \mathrm{M}$.

In the current study, the AXT which are next-generation antioxidative components have been attracting great attention in the entire bioindustry such as food, medicines, and cosmetics industries. The major function of AXT is antioxidative activity. Its ability to remove $\mathrm{O}_{2}$ is excellent to the extent that it is comparable to that of $\alpha$-tocopherol and it plays the role of preventing lipid oxidation from occurring in cell membranes [25]. Astaxanthin suppresses damage to intracellular DNA, proteins, and lipids by active oxygen as well as tissue aging and carcinogenesis and plays the role of suppressing the formation of free radicals [27].

In summary, the results suggest that all experimental groups added with AXT showed significantly higher motility and progressive motility compared to the control group $(p<0.05)$ (Table 1). According to the results of analyses of oxidative substances in pig sperm conducted using FACS, the experimental groups added with AXT had generally lower values than the control group but did not have any significantly better ability to remove $\mathrm{O}_{2}$ and $\mathrm{H}_{2} \mathrm{O}_{2}$ (Table 2). Given that the formation of $\mathrm{H}_{2} \mathrm{O}_{2}$ was suppressed in the patterns of formation of active oxygen in the experimental groups added with AXT, the effects of $\mathrm{H}_{2} \mathrm{O}_{2}$ seem to account 


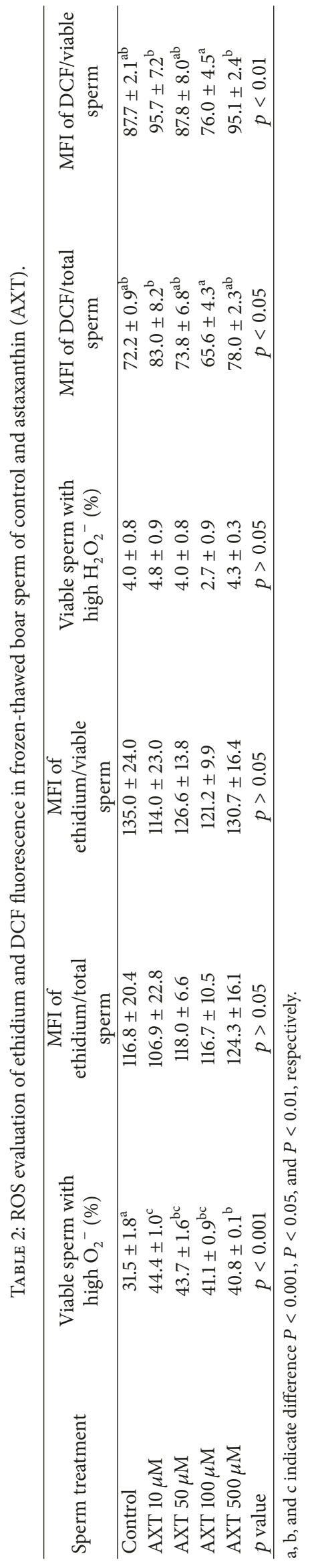


for more of the harmfulness of freezing of pig sperm than do the effects of $\mathrm{O}_{2}$.

Based on the results of the present experiments, the addition of astaxanthin as antioxidants to frozen storage solutions in the manufacturing of frozen miniature pig semen protected sperm from damage in the freeze-thawing process, maintained sperm motility, and prevented lipid oxidation to improve sperm metabolic activity and functions.

\section{Conclusion}

It could be seen that astaxanthin added to frozen storage solutions when frozen miniature pig semen was manufactured improved sperm motility and antioxidative effects. The experimental groups added with AXT showed significantly higher motility compared to the control group. In particular, in the experimental group added with AXT at a concentration of $500 \mu \mathrm{M}, 66 \pm 1.7 \%$ of sperm showed movements and $45.7 \pm 2.5 \%$ of sperm showed normal movements. In addition, the experimental group added with AXT at a concentration of $100 \mu \mathrm{M}$ showed the highest efficiency in removing free radicals. The results of the present study are thought to be importantly used in the manufacturing of frozen miniature pig sperm for increasing reproductive cells and livestock propagation. Future studies utilizing diverse additives and antioxidants for improving sperm functions after freezethawing are considered necessary.

\section{Conflicts of Interest}

The authors declare that there are no conflicts of interest regarding the publication of this paper.

\section{Acknowledgments}

The authors would like to thank Dr. Park, JK, for AXT supply and Dr. Park, CK, for semen supply. This work was supported by a grant from Bio-Health Solution RIS Agency, Ministry of Trade Industry \& Energy (R0001090), and the National Research Foundation of Korea (NRF) (Grant no. NRF-20120001770).

\section{References}

[1] L.-M. Houdebine, "Use of transgenic animals to improve human health and animal production," Reproduction in Domestic Animals, vol. 40, no. 4, pp. 269-281, 2005.

[2] T. Okazaki and M. Shimada, "New strategies of boar sperm cryopreservation: Development of novel freezing and thawing methods with a focus on the roles of seminal plasma," Animal Science Journal, vol. 83, no. 9, pp. 623-629, 2012.

[3] S. Chatterjee and C. Gagnon, "Production of reactive oxygen species by spermatozoa undergoing cooling, freezing, and thawing," Molecular Reproduction and Development, vol. 59, no. 4, pp. 451-458, 2001.

[4] N. Cormier, M.-A. Sirard, and J. L. Bailey, "Premature capacitation of bovine spermatozoa is initiated by cryopreservation," Journal of Andrology, vol. 18, no. 4, pp. 461-468, 1997.
[5] J. K. Critser and L. E. Mobraaten, "Cryopreservation of murine spermatozoa," ILAR Journal, vol. 41, no. 4, pp. 197-206, 2000.

[6] L. Fraser and J. Strzezek, "Is there a relationship between the chromatin status and DNA fragmentation of boar spermatozoa following freezing-thawing?" Theriogenology, vol. 68, no. 2, pp. 248-257, 2007.

[7] R. H. Hammerstedt, J. K. Graham, and J. P. Nolan, "Cryopreservation of mammalian sperm: what we ask them to survive," Journal of Andrology, vol. 11, no. 1, pp. 73-88, 1990.

[8] T. Kaneko, A. Yamamura, Y. Ide, M. Ogi, T. Yanagita, and N. Nakagata, "Long-term cryopreservation of mouse sperm," Theriogenology, vol. 66, no. 5, pp. 1098-1101, 2006.

[9] M. P. Rosato and N. Iaffaldano, "Cryopreservation of rabbit semen: Comparing the effects of different cryoprotectants, cryoprotectant-free vitrification, and the use of albumin plus osmoprotectants on sperm survival and fertility after standard vapor freezing and vitrification," Theriogenology, vol. 79, no. 3, pp. 508-516, 2013.

[10] R. J. Aitken, K. T. Jones, and S. A. Robertson, "Reactive oxygen species and sperm function-in sickness and in health," Journal of Andrology, vol. 33, no. 6, pp. 1096-1106, 2012.

[11] L. R. Abeydeera, "In vitro production of embryos in swine," Theriogenology, vol. 57, no. 1, pp. 257-273, 2002.

[12] A. K. Bansal and G. S. Bilaspuri, "Impacts of oxidative stress and antioxidants on semen functions," Veterinary Medicine international, vol. 2010, Article ID 686137, 7 pages, 2010.

[13] L. Fraser and J. Strzezek, "Effects of freezing-thawing on DNA integrity of boar spermatozoa assessed by the neutral comet assay," Reproduction in Domestic Animals, vol. 40, no. 6, pp. 530536, 2005.

[14] F. Chen, K. Sun, and L. Li, "Research status and development trend of miniature piezoelectric energy harvesting devices," Journal of Hubei Polytechnic University, vol. 27, pp. 1-4, 2012.

[15] J. G. Alvarez and B. T. Storey, "Evidence for increased lipid peroxidative damage and loss of superoxide dismutase activity as a mode of sublethal cryodamage to human sperm during cryopreservation," Journal of Andrology, vol. 13, no. 3, pp. 232241, 1992.

[16] M. Mortazavi, I. Salehi, Z. Alizadeh, M. Vahabian, and A. M. Roushandeh, "Protective effects of antioxidants on sperm parameters and seminiferous tubules epithelium in high fat-fed rats," Journal of Reproduction and Infertility, vol. 15, no. 1, pp. 22-28, 2014.

[17] C. O'Flaherty, M. Beconi, and N. Beorlegui, "Effect of natural antioxidants, superoxide dismutase and hydrogen peroxide on capacitation of frozen-thawed bull spermatozoa," Andrologia, vol. 29, no. 5, pp. 269-275, 1997.

[18] F. J. Peña, A. Johannisson, M. Wallgren, and H. Rodriguez Martinez, "Antioxidant supplementation of boar spermatozoa from different fractions of the ejaculate improves cryopreservation: changes in sperm membrane lipid architecture," Zygote, vol. 12, no. 2, pp. 117-124, 2004.

[19] E. Estrada, M. M. Rivera del Álamo, J. E. Rodríguez-Gil, and M. Yeste, "The addition of reduced glutathione to cryopreservation media induces changes in the structure of motile subpopulations of frozen-thawed boar sperm," Cryobiology, vol. 78, pp. 56-64, 2017.

[20] L. Ernster, P. Forsmark, and K. Nordenbrand, "The mode of action of lipid-soluble antioxidants in biological membranes: relationship between the effects of ubiquinol and vitamin $\mathrm{E}$ as inhibitors of lipid peroxidation in submitochondrial particles," BioFactors, vol. 3, no. 4, pp. 241-248, 1992. 
[21] P. Thérond, J. Auger, A. Legrand, and P. Jouannet, " $\alpha$-tocopherol in human spermatozoa and seminal plasma: relationships with motility, antioxidant enzymes and leukocytes," Molecular Human Reproduction, vol. 2, no. 10, pp. 739-744, 1996.

[22] M. N. Bucak, A. Ateşşahin, Ö. Varişli, A. Yüce, N. Tekin, and A. Akçay, "The influence of trehalose, taurine, cysteamine and hyaluronan on ram semen. Microscopic and oxidative stress parameters after freeze-thawing process," Theriogenology, vol. 67, no. 5, pp. 1060-1067, 2007.

[23] M. Guerin, M. E. Huntley, and M. Olaizola, "Haematococcus astaxanthin: Applications for human health and nutrition," Trends in Biotechnology, vol. 21, no. 5, pp. 210-216, 2003.

[24] M. Kurashige, E. Okimasu, M. Inoue, and K. Utsumi, "Inhibition of oxidative injury of biological membranes by astaxanthin," Physiological Chemistry and Physics and Medical NMR, vol. 22, no. 1, pp. 27-38, 1990.

[25] P. Di Mascio, T. P. A. Devasagayam, S. Kaiser, and H. Sies, "Carotenoids, tocopherols and thiols as biological singlet molecular oxygen quenchers," Biochemical Society Transactions, vol. 18, no. 6, pp. 1054-1056, 1990.

[26] Y. M. A. Naguib, "Antioxidant activities of astaxanthin and related carotenoids," Journal of Agricultural and Food Chemistry, vol. 48, no. 4, pp. 1150-1154, 2000.

[27] P. Palozza and N. I. Krinsky, "Astaxanthin and canthaxanthin are potent antioxidants in a membrane model," Archives of Biochemistry and Biophysics, vol. 297, no. 2, pp. 291-295, 1992.

[28] N. Tran, J. Park, S. Hong, and C. Lee, "Proteomics of proteins associated with astaxanthin accumulation in the green algae Haematococcus lacustris under the influence of sodium orthovanadate," Biotechnology Letters, vol. 31, no. 12, pp. 1917-1922, 2009.

[29] E.-K. Park and C.-G. Lee, "Astaxanthin production by Haematococcus pluvialis under various light intensities and wavelengths," Journal of Microbiology and Biotechnology, vol. 11, no. 6, pp. 1024-1030, 2001.

[30] E. Tvrdá, Z. Kňažická, L. Bárdos, P. Massányi, and N. Lukáč, "Impact of oxidative stress on male fertility - A review," Acta Veterinaria Hungarica, vol. 59, no. 4, pp. 465-484, 2011.

[31] E. Aisen, M. Quintana, V. Medina, H. Morello, and A. Venturino, "Ultramicroscopic and biochemical changes in ram spermatozoa cryopreserved with trehalose-based hypertonic extenders," Cryobiology, vol. 50, no. 3, pp. 239-249, 2005.

[32] J.-L. Liu, H. Kusakabe, C.-C. Chang et al., "Freeze-dried sperm fertilization leads to full-term development in rabbits," Biology of Reproduction, vol. 70, no. 6, pp. 1776-1781, 2004.

[33] M. Yeste, "Sperm cryopreservation update: Cryodamage, markers, and factors affecting the sperm freezability in pigs," Theriogenology, vol. 85, no. 1, pp. 47-64, 2016.

[34] M. S. Lehti and A. Sironen, "Formation and function of sperm tail structures in association with sperm motility defects $\uparrow, "$ Biology of Reproduction, vol. 97, no. 4, pp. 522-536, 2017.

[35] J. G. Alvarez and B. T. Storey, "Role of glutathione peroxidase in protecting mammalian spermatozoa from loss of motility caused by spontaneous lipid peroxidation," Gamete Research, vol. 23, no. 1, pp. 77-90, 1989.

[36] M. T. Beconi, C. R. Francia, N. G. Mora, and M. A. Affranchino, "Effect of natural antioxidants on frozen bovine semen preservation," Theriogenology, vol. 40, no. 4, pp. 841-851, 1993.

[37] E. M.-E. Aboagla and T. Terada, "Trehalose-enhanced fluidity of the goat sperm membrane and its protection during freezing," Biology of Reproduction, vol. 69, no. 4, pp. 1245-1250, 2003. 


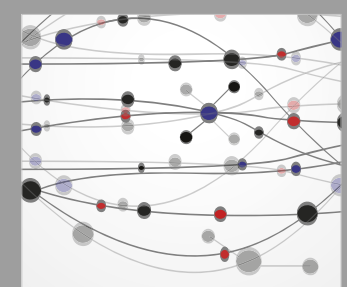

The Scientific World Journal
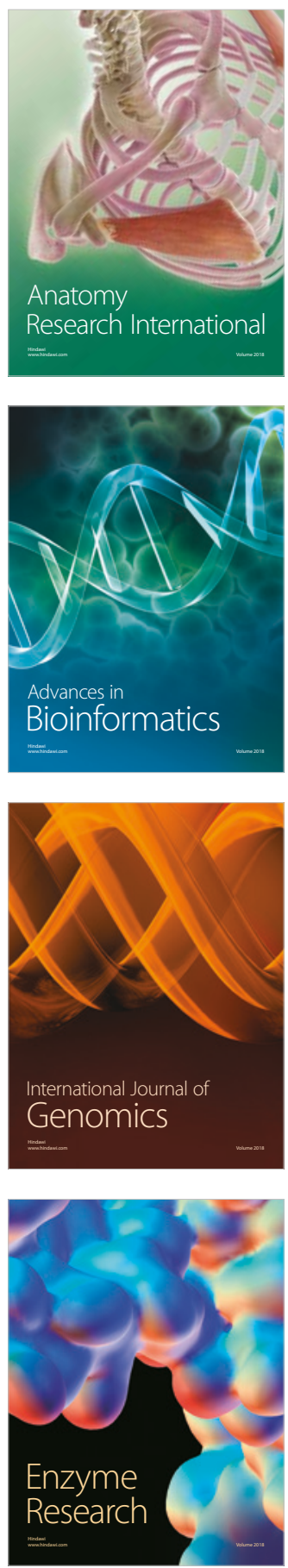
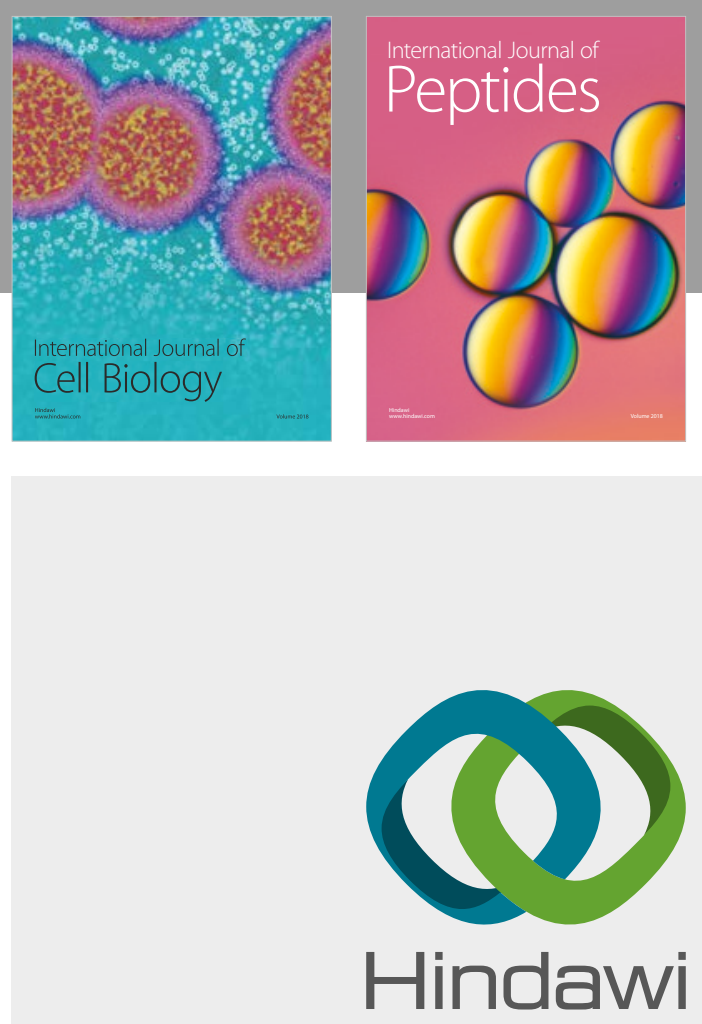

Submit your manuscripts at

www.hindawi.com
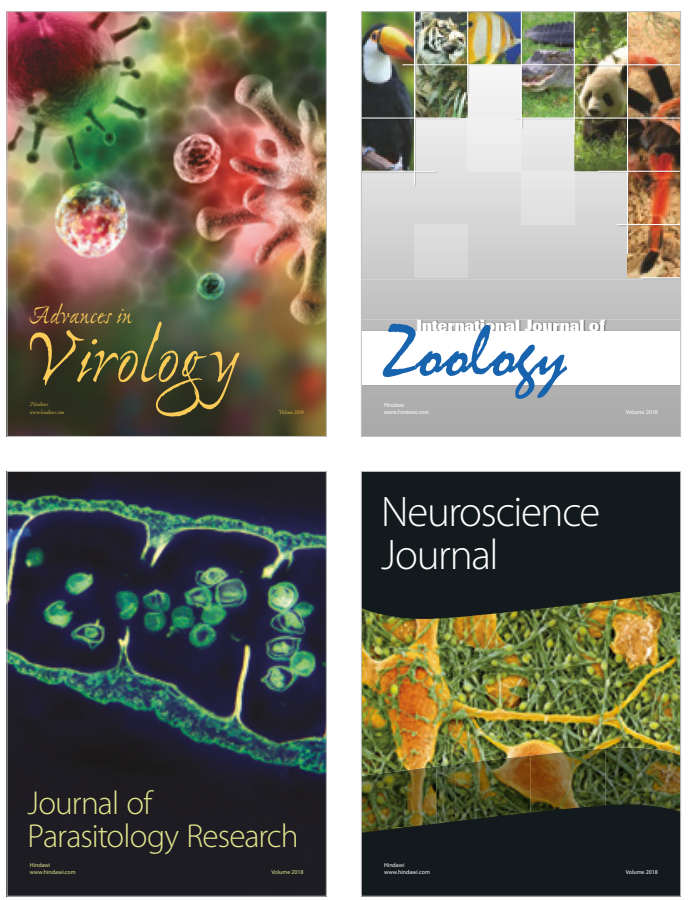
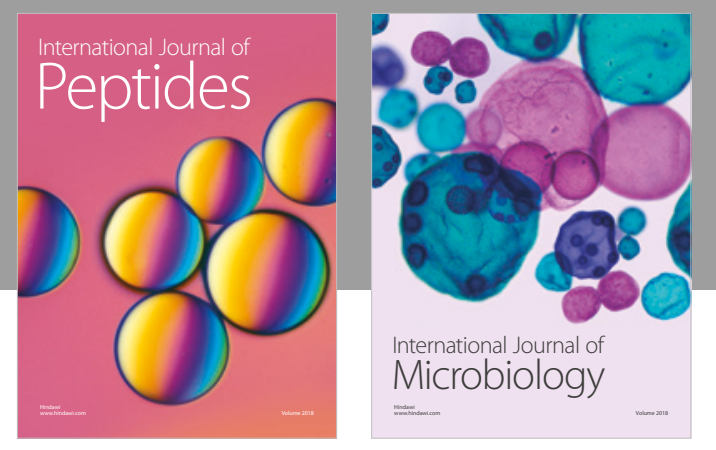

nternational Journal of Microbiology
Journal of
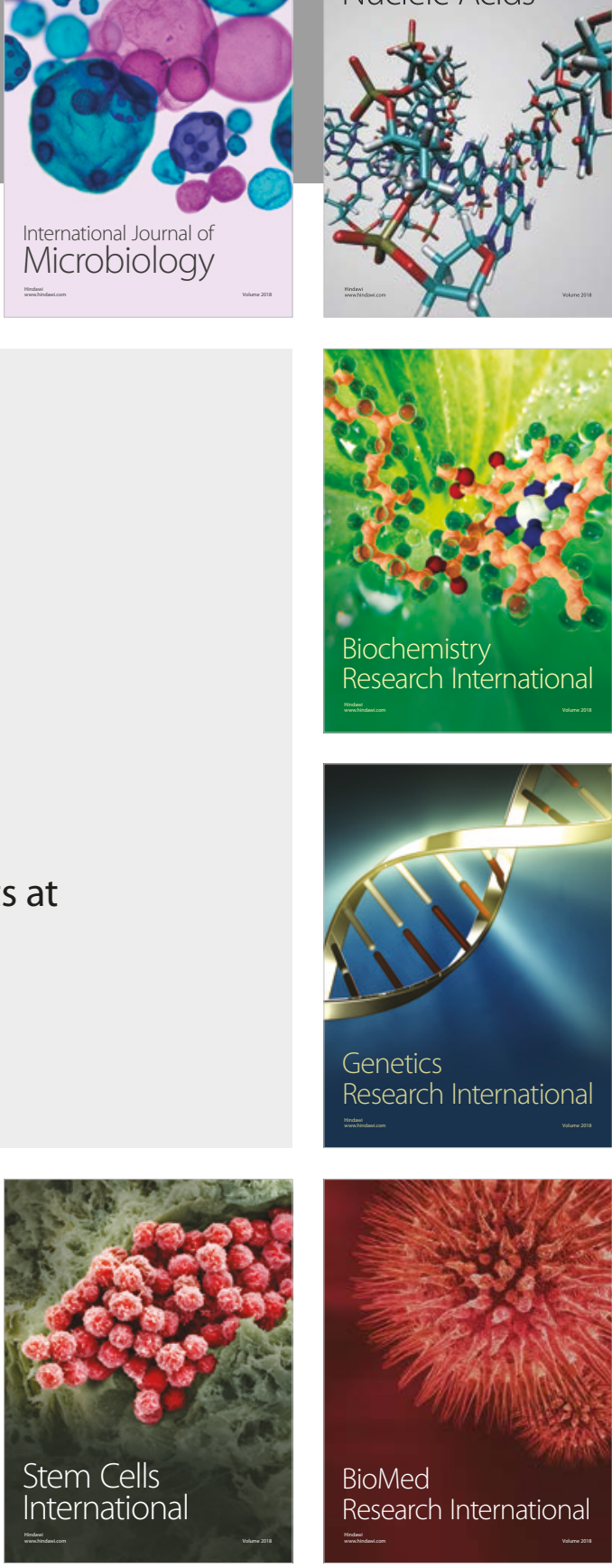
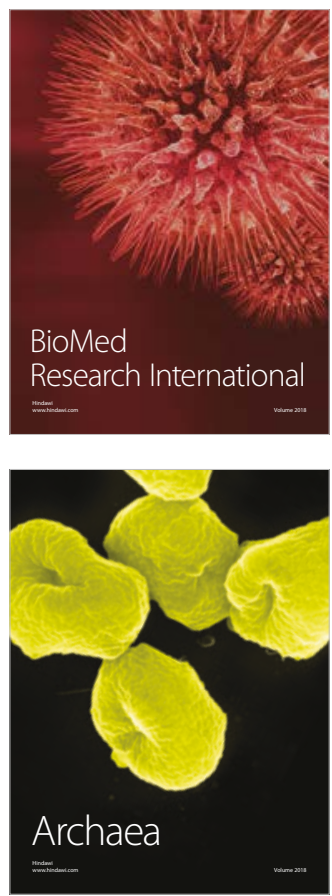